\title{
Premarital Sexual Practice and Risky Sexual Behaviors Associated with it among Secondary School Adolescents, South East Ethiopia: A Mixed Design Study
}

Duressa Endalew ${ }^{1 *}$, Bereket Gebremichael ${ }^{2}$ MulugetaTesfa $^{3}$ and Tarekegn Asmamaw ${ }^{3}$

${ }^{1}$ Department of Health System, Ethiopian Public Health Institute, Addis Ababa, Ethiopia

${ }^{2}$ College of Health Sciences, Addis Ababa University, Addis Ababa, Ethiopia

${ }^{3}$ College of Medicine and Health Science, Debre Markos University, Debemarkos, Ethiopia

\begin{abstract}
Background: Adolescence is the journey of transition from childhood to adulthood at which mental, emotional, social and psychosexual development occurs. Early initiation to sexual intercourse without having proper protection has been one of the concerns. Previous studies in Ethiopia indicated significant numbers of adolescents are sexually active and only about $40 \%$ of them reported consistent use of condom which exposes them to various form of reproductive health risk. Therefore the main aim of this study was to assess premarital sexual practices and sexual and reproductive health risks associated with it among secondary school adolescents.
\end{abstract}

Methods: School based cross-sectional study design supported by qualitative survey was used. A total of 702 study participant was selected by multi stage sampling technique. Structured questionnaire and focus group discussion were used to collect the data. Finally data were entered using Epi info version 7 and analyzed using SPSS version 20.

Result: The Magnitude of premarital sexual practice was $136(20.6 \%)$ from which 99 (72.8\%) were males. Mean age at first sexual initiation was found to be 15.5. Being male (AOR $[95 \% \mathrm{Cl}]=4.60[2.25,9.67])$, having pocket money $(A O R[95 \% \mathrm{Cl}]=2.86[1.45,5.63])$, watching pornographic movies $(\mathrm{AOR}[95 \% \mathrm{Cl}]=2.82[1.30,6.13])$, and drinking alcohol $(\mathrm{AOR}[95 \% \mathrm{Cl}]=1.99[1.01,3.91])$ were found to have association with premarital sexual practice.

Conclusion: The study reflected the prevalence of pre-marital sexual practices was high. Therefore there should be control over local cinemas, movie renting shops and groceries to decrease exposure of adolescents for pornographic movies and alcohols.

Keywords: Adolescence; Reproductive health risk; Premarital sexual practice; Secondary school

\section{Introduction}

\section{Background}

The World Health Organization (WHO) defines adolescents as those between the ages of 10 to 19 years [1]. Sexuality is among many development events of human being that occurs since the onset of puberty, which marks the entry into the period of adolescence. Adolescence is the journey of transition from childhood to adulthood and it is the time of physical, mental, emotional, social and psychosexual development [2]. In addition, adolescence is a period of great opportunity because it is during this period that adolescents develop ability to contribute positively to their own lives and to those of their families and communities. On the other hand, adolescence is a time of risks that many important life events and health-damaging behaviors occur during adolescence years than any other stage of development [3].

In Ethiopia, adolescents aged 10 to 20 years constitute 25\% of the population [4]. According to the 2007 Ethiopian census, youths aged 15-24 years were more than 15.2 million which contributes to $20.6 \%$ of the whole population. These very large and productive groups of the population are frequently exposed to various forms of sexual and reproductive health risks including, sexual coercion, early marriage or sexual debut, female genital cutting, unplanned pregnancies, closely spaced pregnancies, abortion, Sexually Transmitted Infections (STIs), and HIV/AIDS [5].

Sexual activities among adolescents have been reported to be increasing worldwide. Several studies in Sub Saharan Africa have also documented high and increasing premarital sexual activities among adolescents [5].

Youth who begin early sexual activity are more likely to have highrisk sex or multiple partners and are less likely to use condoms [6]. One in every 10 births and one in 10 abortions worldwide and one in six births in developing countries are to women age between15-19years. Each day half a million of young people are infected with asexually transmitted disease [7]. Nearly 12 million young people are living with HIV/AIDS; and more than 7,000 young people become infected with HIV every day [8].

Risky sexual behavior or unsafe sex due to failure to use condoms and birth control methods undoubtedly increase risk of unwanted pregnancy, abortion or contracting STDs including HIV/AIDS. As evidenced by different studies timing of sexual debut among

*Corresponding author: Duressa Endalew, Department of Health System, Ethiopian Public Health Institute, P. Box 13386, Addis Ababa, Ethiopia; Tel: 251912817670; E-mail: bdpapi2@gmail.com

Received July 13, 2018; Accepted August 30, 2018; Published September 06, 2018

Citation: Endalew D, Gebremichael B, Tesfa M, Asmamaw T (2018) Premarita Sexual Practice and Risky Sexual Behaviors Associated with it among Secondary School Adolescents, South East Ethiopia: A Mixed Design Study. J AIDS Clin Res 9: 775. doi: 10.4172/2155-6113.1000775

Copyright: (c) 2018 Endalew D, et al. This is an open-access article distributed under the terms of the Creative Commons Attribution License, which permits unrestricted use, distribution, and reproduction in any medium, provided the original author and source are credited. 
youths is influenced by a wide range of factors including age, gender, residence, educational level, knowledge on HIV, economic status, watching pornography, Khat and alcohol utilization [9]. In Ethiopia, an increasingly large number of adolescents are enrolled in high schools and they often live away from parental guidance. Early initiation of sexual intercourse without having proper protection has been one of the concerns [10].

According to Ethiopian Demographic and Health Survey (EDHS) 2011; among women age 25-49, 29\% first had sexual intercourse before age 15, 62 percent before age 18, and by age 25 the majority of Ethiopian women had had sexual intercourse [5].

Premarital sex is one of the reproductive health problems witnessed in adolescence. Study have revealed that the prevalence of premarital sex among in school youth is higher in Oromia (31.3\%) than the national (19\%) [11].

With the high level of HIV infection and poor sexual and reproductive health outcomes among youths, it is crucial to identify the determinants of sexual activity among the youth. This study focus on premarital sexual practices and sexual and reproductive risk associated with it among in-school youths. Therefore, this study will contribute in filling the gap in understanding premarital sexual practice with its associated sexual and reproductive health problems.

\section{Methods of the Study}

\section{Study area and period}

A school based cross-sectional study supported by qualitative study was conducted in Goba town. The town located in Bale zone Oromia region south east Ethiopia $445 \mathrm{~km}$ away from Addis Ababa. The 2007 national census reported 32,024 of whom 15,182 were men and 16,842 women. There is one hospital and three health centers in the town. There are also two high schools and one preparatory school. The study was conducted from April 1-15 2016.

The source populations were in-school adolescentsin Goba town in the year 2014/2015 and study populations were in-school adolescents whose age was between 15 and 19 in Goba town in the year 2015/2016.

All regular students attending their regular education at the time of data collection were included.

To determine the sample size, single population proportion formula was used based on the assumption of $31 \%$ prevalence (p) in school youth premarital sex in the region [12], at 95\% confidence level $(\mathrm{Za} / 2)^{2}$, a 5\% marginal error (d). Since multistage sampling was employed, the calculated sample was multiplied by 2 for design effects to control the effect of sampling error that could happen due to using sampling method other than simple random sampling, and $10 \%$ contingency for non respondents were also added. Finally, the final sample size became 702 .

\section{Sampling technique and procedure}

Two high schools and one preparatory schoolwere included in the study. There were a total of 1488 students in 31 sections in Goba high school, 374 students in 6 sections in Finchabamo High School and 628 students in Batu Terara Preparatory School. The total sample was distributed to these schools proportionate to their student population size. The number of sampled students were calculated from each school and divided in to grades, $\left(9^{\text {th }}, 10^{\text {th }}, 11^{\text {th }}, 12^{\text {th }}\right)$. Among all sections, 24 sections were randomly selected (5 sections from Batu Terara Preparatory School, 16 sections from Goba high school, and 3 sections from Fincha Bamo high school) and the samples assigned to each school were distributed proportionately into sections and sexes. Then the selected students were invited to participate in the survey.

For FGD, Groups sequestered by sex were organized. The Participants were chosen by purposive method. The participants were in the age range of 15-19 years so that the discussants reflect the sexual experience, determinant factors and reproductive health risks related with premarital sexual experience. First it was planned to conduct at least one male and one female FGD at each grade level but ahead of time since the information were saturated only six focus group discussions were conducted.

Structured and semi structured questionnaire consisting both open and close ended questions were used to collect the data. Most of the questions were adapted from previous studies. Information about student's premarital sexual practice and knowledge of the risks associated with it in general and other related data were collected. This questionnaire also contains respondents and their parent's background information, use of contraceptive method, major factors contributing for the involvement of respondents into sexual activities and other related issues.

In order to support information collected through structured questionnaire, focus group discussions were used. Guiding question were prepared to facilitate the FGD. Questionnaire and questions for FGD guide lines were prepared in English. After the preparations of the questionnaire and questions for FGD guide lines in English, translations was made in to Amharic and afaan Oromo and translation was done. back to English language to check consistency. Students were selected randomly from each section. One moderator guided the discussion and the researcher introduced topics prepared for discussion and clarified concepts whenever needed during the discussion.

\section{Variables}

Premarital sexual practice is dependent variable and Sociodemographic characteristics (religion, age, sex, educational status), Peer pressure, Substance use and Family Background like Parents' education, Parents occupation, Parent-child communication, Living arrangement, and Place of residence are independent variable.

A brief orientation session about the whole purpose of the research was given for all participants. The questionnaire was translated in to Amharic, afaan Oromo and back to English by a translator who was blind to the original questionnaire. Pretest was done on five percent of the sample in similar area (in robe town high school which was $12 \mathrm{~km}$ far from the study area) before the actual data collection took place and correction on instruments was done accordingly. Overall activity was supervised by principal investigator. The quantitave data was checked for completeness and consistency on a daily basis. The data was cleaned and entered by principal investigator.

The data was checked for completeness and consistencies and cleaned, coded and entered using Epi Info version 7 and was exported to Statistical Package for Social Sciences (SPSS) software version 20 for analysis. Descriptive statistics was used to describe the study population in relation to relevant variable. Odds Ratio (OR) was used to assess the relationship between factors associated with premarital sexual practice. All variables with a significant association in the binary logistic regression analysis were included in the final multivariable model to control confounder. Statistical significance was declared at $p<0.05$.The qualitative data was transcribed and separated to different themes based on guide lines and summarized manually. 
Page 3 of 7

\section{Result}

\section{Socio-demographic characteristics of the respondents}

A total of 702 in school adolecsents were included in the study and 690 (98.2\%) responded, But 34 (4.8\%) responses were discarded because of incomplete response. The final response rate was 656 (93.4\%).

Among the total respondents $332(50.6 \%)$ were males. From the respondents 229 (34.9\%), $258(39.3 \%), 89(13.6 \%)$ and $80(12.2 \%)$ were grade nine, ten, eleven and twelve respectively. Majority of the respondents were orthodox 517 (78.8\%) by religion, 413 (63.0\%), were oromoby ethnicity. From the total respondents 373 (56.9\%) live with their both parents. 521 (79.4\%) of the respondents families live in the urban area (Table 1).

Two hundred twenty two (33.8\%) and 134 (20.4\%) of respondents family has completed higher education (father and mother). Regarding occupation majority of the respondents family were government or private employee and house wives (father and mother). 441 (67.2\%) of respondents families live together (Table 2).

\section{Sexual history of the adolescents}

Among all in school adolecsents who are included in the study 136 (20.6\%) from which 99 (72.8\%) males were sexually active during or

\begin{tabular}{|c|c|c|c|}
\hline \begin{tabular}{|l|} 
Variable \\
variables
\end{tabular} & $\begin{array}{l}\text { Category } \\
\text { category }\end{array}$ & $\begin{array}{l}\text { Frequency } \\
\text { frequency }\end{array}$ & $\begin{array}{l}\text { Percentage } \\
\text { percentage }\end{array}$ \\
\hline \multirow[t]{2}{*}{ Sex } & Male & 332 & 50.6 \\
\hline & female & 324 & 49.4 \\
\hline \multirow[t]{5}{*}{ Age } & 15 & 59 & 9.0 \\
\hline & 16 & 160 & 24.4 \\
\hline & 17 & 199 & 30.3 \\
\hline & 18 & 162 & 24.7 \\
\hline & 19 & 76 & 11.6 \\
\hline \multirow[t]{4}{*}{ Grade } & 9 & 299 & 34.9 \\
\hline & 10 & 258 & 39.3 \\
\hline & 11 & 89 & 13.6 \\
\hline & 12 & 80 & 12.2 \\
\hline \multirow[t]{4}{*}{ Ethnicity } & Oromo & 413 & 63.0 \\
\hline & Amhara & 203 & 30.9 \\
\hline & Tigre & 33 & 5.0 \\
\hline & Other & 7 & 1.1 \\
\hline \multirow[t]{4}{*}{ religion } & Orthodox & 517 & 78.8 \\
\hline & Protestant & 70 & 10.7 \\
\hline & Muslim & 57 & 8.7 \\
\hline & Catholic & 12 & 1.8 \\
\hline \multirow[t]{6}{*}{ Live with } & Father and mother & 373 & 56.9 \\
\hline & Mother only & 131 & 20.0 \\
\hline & Relatives & 56 & 8.5 \\
\hline & alone & 52 & 7.9 \\
\hline & Father only & 26 & 4.0 \\
\hline & friends & 18 & 2.7 \\
\hline \multirow[t]{2}{*}{ Pocket money } & yes & 268 & 40.9 \\
\hline & no & 388 & 59.1 \\
\hline \multirow{4}{*}{$\begin{array}{l}\text { Ideal age of } \\
\text { marriage }\end{array}$} & $10-14$ & 2 & 0.3 \\
\hline & $15-19$ & 112 & 17.1 \\
\hline & $20-24$ & 241 & 36.7 \\
\hline & 25 and over & 301 & 45.8 \\
\hline
\end{tabular}

Table 1: Socio-demographic characteristics of the study population; Goba town 2016 G.C $(N=656)$.

\begin{tabular}{|c|c|c|c|}
\hline Variables & Category & frequency & percentage \\
\hline \multirow[t]{2}{*}{ Parents live } & Urban & 521 & 79.4 \\
\hline & Rural & 135 & 20.6 \\
\hline \multirow[t]{2}{*}{ Mother alive } & Yes & 626 & 95.4 \\
\hline & No & 30 & 4.6 \\
\hline \multirow[t]{5}{*}{ Mother education } & Secondary $(9-12)$ & 183 & 27.9 \\
\hline & Primary (1-8) & 164 & 25.0 \\
\hline & Higher & 134 & 20.4 \\
\hline & Read And Write & 88 & 13.4 \\
\hline & $\begin{array}{l}\text { No Formal } \\
\text { Education }\end{array}$ & 57 & 8.7 \\
\hline \multirow{5}{*}{$\begin{array}{l}\text { Mother } \\
\text { occupation }\end{array}$} & House Wife & 295 & 45.0 \\
\hline & Employed & 151 & 23.0 \\
\hline & Merchant & 112 & 17.1 \\
\hline & Farmer & 58 & 8.8 \\
\hline & Daily Laborer & 10 & 1.5 \\
\hline \multirow[t]{2}{*}{ Father alive } & Yes & 545 & 83.1 \\
\hline & No & 111 & 16.3 \\
\hline \multirow[t]{5}{*}{ Father education } & Higher & 222 & 33.8 \\
\hline & Secondary(9-12) & 149 & 22.7 \\
\hline & Primary(1-8) & 119 & 18.1 \\
\hline & Read And Write & 47 & 7.2 \\
\hline & $\begin{array}{l}\text { No Formal } \\
\text { Education }\end{array}$ & 10 & 1.5 \\
\hline \multirow[t]{5}{*}{ father occupation } & Employed & 310 & 47.3 \\
\hline & Merchant & 104 & 15.9 \\
\hline & Farmer & 97 & 14.8 \\
\hline & Daily Laborer & 24 & 3.7 \\
\hline & Other & 10 & 1.5 \\
\hline \multirow{7}{*}{$\begin{array}{l}\text { Family income } \\
\text { (ETB) }\end{array}$} & $3551-5000$ & 161 & 24.5 \\
\hline & $651-1400$ & 149 & 22.7 \\
\hline & $1401-2350$ & 103 & 15.7 \\
\hline & $2351-3550$ & 96 & 14.6 \\
\hline & $>5000$ & 89 & 13.6 \\
\hline & $151-650$ & 46 & 7.0 \\
\hline & $0-150$ & 12 & 1.8 \\
\hline \multirow[t]{3}{*}{ Marital status } & Married & 441 & 67.2 \\
\hline & Widowed & 122 & 18.6 \\
\hline & Divorced & 93 & 14.2 \\
\hline
\end{tabular}

Table 2: Description of parents' characteristics of study population: Goba town 2016 G.C $(N=656)$.

before the study period, 424 (64.6\%) of them has have seen or read pornographic movies or magazines that focus on sex. And 303 (46.2\%) of them have boy or girl friend. Regarding age at first sexual initiation from the responents who were sexually active $64(47.1 \%)$ started sexual intercourse at the age of 15 years. Seventy six (55.9\%) had thier first sex with a partner of the same age. Coming to the main reason of having sex falling in love holds 69 (50.7\%) followed by sexual desire 28 (20.6\%), to get married $17(12.5 \%)$, peer pressure 8 (5.9\%), was drunk 6 (4.4\%), raped $4(2.9 \%)$ and other 4 (2.9\%). From the respondents who were sexually active 59 (43.4\%) started sexual intercourse with boy/ girl friend out of school. One hundred thirty six adolescents who were sexually active, gave response to the question enquiring the number of their sexual partners they had accordingly; only one 58 (42.6\%) three and above 41 (30.1\%) and two 37 (27.2\%) (Table 3).

Among adolescents who are sexually active only 75 (55.1\%) of them used condom on their first sexual intercourse and $83(61.0 \%)$ of them used it in the last 12 months. From those who used condom in the last 12 months only 61 (73.5\%) used it always. The reasons given for not using condom; don't like to use 24 (27.9\%) was the most frequent 
response followed by decrease satisfaction $22(25.5 \%)$, trusting partner $16(18.6 \%)$, ashamed to ask partner $9(10.5 \%)$, ashamed to buy $5(5.8 \%)$, prohibited by religion $5(5.8 \%)$, condom was not available $4(4.6 \%)$ and it bursts 1 (1.2\%) (Figure 1).

\section{Results of multiple logistic regression}

Association between dependent and every independent variable were tested with binary logistic regression. From these it is observed that male sex, living arrangement, place of residence of family, alcohol consumption, pocket money, watching sexual movies, having boy/ girl friend and discussing sexual and reproductive health issues were observed to have association with premarital sexual practice.

\begin{tabular}{|c|c|c|c|}
\hline Variables & Category & Frequency & Percentage \\
\hline \multirow[t]{2}{*}{ Seen sexual movie } & Yes & 422 & 64.6 \\
\hline & No & 234 & 35.4 \\
\hline \multirow[t]{2}{*}{ Have boy/girl friend } & Yes & 303 & 46.2 \\
\hline & No & 353 & 53.8 \\
\hline \multirow[t]{2}{*}{ Have sex } & Yes & 136 & 20.7 \\
\hline & No & 520 & 79.3 \\
\hline \multirow[t]{4}{*}{ Age of person } & Same Age & 76 & 55.9 \\
\hline & Older Than Me & 34 & 25.0 \\
\hline & I Don't Know & 22 & 16.2 \\
\hline & Younger Than Me & 4 & 2.9 \\
\hline \multirow[t]{8}{*}{ Reason for sex } & Love & 69 & 50.7 \\
\hline & Sexual Desire & 28 & 20.6 \\
\hline & To Get Married & 17 & 12.5 \\
\hline & Peer Pressure & 8 & 5.9 \\
\hline & Was Drunk & 6 & 4.4 \\
\hline & Raped & 4 & 2.9 \\
\hline & To Get Money Or Gift & 3 & 2.2 \\
\hline & Other & 1 & 0.7 \\
\hline \multirow[t]{4}{*}{ First sexual partner } & Boy/ Girlfriend Out Of School & 59 & 43.4 \\
\hline & School Boy/ Girl Friend & 54 & 39.7 \\
\hline & Relative & 13 & 9.6 \\
\hline & Married Person & 10 & 7.4 \\
\hline
\end{tabular}

Table 3: Sexual history of respondents: Goba town, 2016 G.C (N=656).
To control confounders and identify the actual factors that are associated with premarital sexual practice variables that had association on univariate binary logistic regression were selected and entered to multivariable binary logistic regression and the result showed that sex, alcohol consumption, pocket money, watching sexual movies and having boy/girl friend are strongly associated with premarital sexual practice.

Male respondents were four times more likely (AOR $4.6[95 \%$ CI 2.25, 9.67]) to practice premarital sexual practice. On the other hand alcohol consumption was also observed to have association with premarital sexual practice: i.e. those who consume alcohol are two times more likely (AOR 1.99 [95\% CI 1.01, 3.91]) more likely experienced premarital sexual practice than those who didn't consume alcohol (Table 4).

Respondents who have pocket money are two times more likely (AOR 2.86 [CI 95\% 1.45, 5.63]) to practice premarital sexual practice than those who don't have (Table 4).

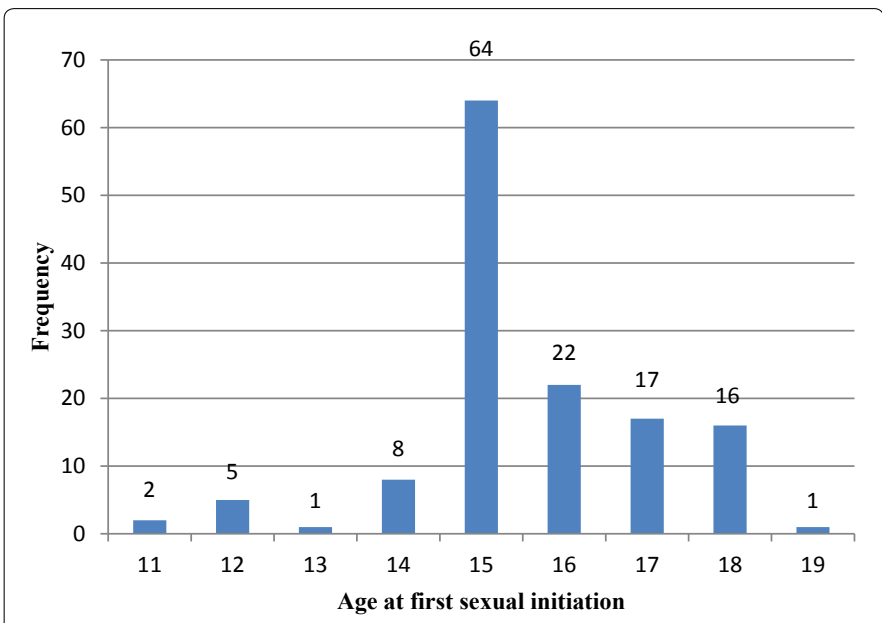

Figure 1: Age at first sexual initiation of respondets: Goba town, 2016.

\begin{tabular}{|c|c|c|c|c|c|}
\hline \multirow[b]{2}{*}{ Variables } & \multirow[b]{2}{*}{ Categories } & \multicolumn{2}{|c|}{ Premarital sex } & \multirow{2}{*}{$\begin{array}{c}\text { COR } \\
(95 \% \mathrm{Cl})\end{array}$} & \multirow{2}{*}{$\begin{array}{c}\text { AOR } \\
(95 \% \mathrm{Cl})\end{array}$} \\
\hline & & Yes & No & & \\
\hline \multirow[b]{2}{*}{ Sex } & Male & 99 & 223 & $3.29(2.17,4.99)^{*}$ & $4.60(2.25,9.67)^{*}$ \\
\hline & Female & 37 & 287 & 1 & 1 \\
\hline \multirow[t]{2}{*}{ Parents live } & Rural & 36 & 99 & 1 & 1 \\
\hline & Urban & 100 & 421 & $0.65(0.42,1.02)$ & $3.08(1.28,7.69)^{*}$ \\
\hline \multirow[t]{2}{*}{ Live with } & Mother And Father & 59 & 224 & 1 & 1 \\
\hline & Other & 77 & 296 & $2.70(3.52,5.51)^{\star}$ & $2.90(2.01,3.85)^{\star}$ \\
\hline \multirow[t]{2}{*}{ Drink alcohol } & Yes & 65 & 102 & $3.75(2.52,5.59)^{\star}$ & $1.99(1.01,3.91)^{\star}$ \\
\hline & No & 71 & 418 & 1 & 1 \\
\hline \multirow[t]{2}{*}{ Have pocket money } & Yes & 89 & 179 & $3.60(2.43,5.59)^{*}$ & $2.86(1.45,5.63)^{*}$ \\
\hline & No & 47 & 341 & 1 & 1 \\
\hline \multirow[t]{2}{*}{ Seen sexual movie } & Yes & 116 & 308 & $3.99(2.41,6.62)^{\star}$ & $2.82(1.30,6.13)^{*}$ \\
\hline & No & 20 & 212 & 1 & 1 \\
\hline \multirow[t]{2}{*}{ Have boy/girl friend } & Yes & 110 & 193 & $7.17(4.52,11.38)^{\star}$ & $11.36(5.45,23.68)^{*}$ \\
\hline & No & 26 & 327 & 1 & 1 \\
\hline \multirow[t]{2}{*}{ Discus with family } & Yes & 14 & 94 & $0.52(0.28,0.94)^{*}$ & $0.40(0.15,1.06)$ \\
\hline & No & 122 & 426 & 1 & 1 \\
\hline
\end{tabular}

*- Stastically Variable

Table 4: Factors associated with premarital sexual practice of respondents: Goba town 2016. 


\section{Findings from the FGD}

A total of 42 students were invited to participate in the FGD and 6 FGDs were conducted three FGD for males and three FGD for females respectively. First it was planned to conduct 8 FGDs but after conducting 4 FGDs the information's become repeated (saturated) and for wise management of time and resource only 6 were conducted.

\section{Factors contributing to premarital sexual practice}

There are infinitely many factors that contribute for engagement of adolescents inpremarital sexual practice. One of 18 years old grade 12 female discussants said "since the boys see having girlfriend and having sex with her is sign of modernization they will not give you breathe once they laid their eye on you until they get what they want"

The other factor mentioned by the discussants as a factor for premarital sexual practice is the wearing style of the girls. A 16 years old male participant from grade 9 said "when you see the way the girls dress these days they are almost naked and anyone who see this can be mistaken not only the adolescents but even the older men who are married"

Lack of youth recreation center in the area is another factor mentioned by the discussants one 19 year old male discussant mentioned "there is no recreation center in which you pass your free time as a result students are exposed for different malpractices like chewing khat on Saturdays and Sunday and this lead them to unwanted action"

\section{Risky sexual behaviors}

Some risky sexual activities known are mentioned by the students like unprotected sex, having more than one sexual partner, not using condom and having sexual intercourse with commercial sex workers. The discussants mentioned that specially having more than one sexual partner is becoming fashion.

Another 17 year old grade 9 female participant said "how can I ask my boy friend to use condom unless there is mistrust between us? If my fear is pregnancy I should use another method to prevent that"

Sex under the influence of alcohol and drugs is also mentioned as a risky sexual behavior by discussants 16 year old male discussant from high school mentioned "there are shisha and khat chewing houses in front of schools not only the students but there are also some teachers who use them and there are many unspeakable things that are being done in the back yards of these shops"

One 16 year male participant from grade 10 "now a day the girls are not in fear of pregnancy thanks to marry topes 'yasfeneterutal'

\section{Discussion}

The study revealed that the prevalence of premarital sexual practice was $136(20.6 \%)$ from which $99(72.8 \%)$ were males. The result was in line with other studies in different areas like Alamata and AddisAbaba $[13,14]$. But the figure is little bigger when compared with the 2011 EDHS report of premarital sexual practice of adolescents which is (19\%) [5]. This might be the EDHS is done nation wide and there might variances in different parts of the country.

The mean age of premarital sexual practice among study participants was 15.5 ( $\mathrm{SD} \pm 1.4$ ), this age is somewhat early when compared to a study conducted among School Adolescents in Nekemte Town, East Wollega,north Gondar and youths in GamoGofa [15-17]. But it was found bigger compared to study done on adolescents on Santiago Island, Cape Verde, $14(\mathrm{SD}=2.0)$ and $15(\mathrm{SD} \pm 1.64)$ males and females respectively. The FGD participants also mentioned currently it is very normal to see very young adolescents engaging in premarital sex. The overall results show that the average age of first sexual initiation was decreasing; and sexual intercourse before age of 18 is considered as risky [3].

Being male has its own contributing factor for sexual initiation (AOR 4.61 [95\% CI 2.25, 9.67]) this is the same with other studies in jimma and Addis Ababa where males are two times more likely to practice premarital sex $[18,19]$. This may be due to the cultural influence that males are relatively free to engage in sexual activities and females were expected to keep their virginity till marriage.

Alcohol consumption was found to be another single most important factor which lead to sexual debut (AOR 1.996 [95\% CI 1.01, 3.91]) this result is same as another study done in north east Ethiopia those who drink alcohol were two times more likely to initiate sexual intercourse before the age of 18 and inAddis Ababa alcohol consumers were more likely to practice premarital sex $[16,19]$. One of the FGD participants said "the university students prepare party and invite girls from preparatory and high school the girls doesn't have much experience on alcohol and they get drunk and exposed to unplanned sex". This may be due to when an individual is drunk his/ her ability of self controlling and risk perception decrease.

Modernization and globalization which made things easy has an impact on sexual activity of adolescents. The participants from this study who are sexually active $85.3 \%$ of them were exposed to pornographic movies, this result has similar finding with that of in-school youths of Shendi town [20]. One of the FGD participants mentioned "these days it is very easy to be a friend with a girl because of social medias, the girls themselves post different pictures on their wall which will make you start flirting with them and easily engage in sexual relationship with them." The reason for this may be at youths at this age group need to try what they have heard and read.

Another concern of premarital sexual practice is risky sexual activities like having more than one sexual partner, having sex with commercial sex worker and not using condom. From the study it was observed that among adolescents who were sexually active only $75(55.1 \%)$ of them used condom on their first sexual intercourse the result matches with other findings; Washington, north Ethiopia [21,20]. There are many reasons given by respondents for not using condom from these trusting partner fear to ask were the major ones which were same with other studies: like in-school youths of Shendi town, trusting partner (38.6\%), ashamed to ask partner (24.4\%), fear to buy from shop or pharmacies (16.5\%), partner trust (43\%) and partners disagreement (5.1\%) among school adolescents in Injibara town [2]. The FGD participants also mentioned the above problems. These results show that there is still a gap in condom utilization among adolescents.

In addition to this having sexual intercourse with commercial sex workers was also another risky behavior the in the study area the prevalence was (15.6\%) from these only $(35.7 \%)$ of them used condom consistently; the result is quite higher when compared with some other studies done in different places for example the magnitude of having sexual debut with commercial sex worker among preparatory students of Gondar town was reported 5\% [22].

The other risky sexual behavior mentioned was having more than one sexual partner in the area $57.3 \%$ of the respondents have more than one sexual partner the result is consistent with studies done in United States of America by $10^{\text {th }}$ grade, more than half of sexually initiated males reported having had four or more lifetime sexual partners [8]. The finding from Madawalabu also shows from the total sexually active 
respondents, (33.6\%) had two or more sexual partners [23]. From the FGD participants one of them mentioned that "the girls measure their beauty by the number of males they date and the males think having more than one girl friend is a heroic action" as mentioned by the FGD participants and found from different studies the prevalence of having more than one sexual partner is becoming more common the reason for this may be the effect of globalization and easily accessibility of social medias.

\section{Limitation of the study}

Since the study deals about very sensitive and personal issue and the questioners were self administered there may be response bias.

\section{Conclusion}

In conclusion this study has found that one fifth of students were engaged in premarital sex; male gender, alcohol consumption, having pocket money, watching pornographic movies has significant association with it.

The mean age of first sexual initiation was found to be 15.5 but most of the students start at the age of 15 this shows the youths are at risk of sexual and reproductive health problems since early initiators are more vulnerable.

Some students were practicing risky sexual behaviors like alcohol consumption, having more than one sexual partner having sex with commercial sex workers and not using condom consistently, this would increases vulnerability to sexual and reproductive health problems. This was evidenced by some teen age pregnancies observed in the study and some participants developed signs of STIs.

\section{Recommendation}

Based on the findings and the conclusion the following ideas were recommended. Schools and other concerned body should work in collaboration to address the issure of $\mathrm{RH}$ by establishing youth asscociation in the school or in the community that can increase awareness of the issue.There should also be control over local cinemas and movie renting shops to decrease exposure of adolescents for pornographic movies. Furthermore medias and schools should play a role in promoting child parent communication since it has a positive impact on prevention of premarital sexual debut.

\section{Ethical Considerations}

Ethical clearance was obtained from the ethical review committee of Debre Markos University, Medicine and Health Science College. Then the concerned officials from the zone at each level were communicated through formal letter. In order to ensure privacy, at individual level after explaining the purpose of the study, written consent was obtained from all participants. For those who are under age of 18 and live with their family written consent was sent for their families one day prior to the study, for those families who cannot read and write their children read the consent for them and finger print sign was obtained. Furthermore, investigators informed that their participation in the study is voluntary and that they are not obliged to answer to any questions with which they are uncomfortable. They were free to withdraw their participation from the study at any time they want. Anonymity was maintained to confirm confidentiality.

\section{Funding}

The study was funded by Debre markos University, Ethiopia. The funder has no role in study design, data collection and analysis, interpretation of data, decision to publish, or preparation of the manuscript.

\section{Authors' Contributions}

All authors contributed to the design of the study and the interpretation of data. DE performed the data analysis and compiled the whole work. BG and DE conducted the FGD. BG reviewed the whole work and drafted the manuscript. All authors critically revised the draft manuscript. All authors read and approved the final manuscript.

\section{Acknowledgment}

First of all, we would like to express our deepest gratitude and appreciation for Debre Markos University College of medicine and health science GAMBY College of medical science for their support to undertake this research work. We would also like to extend our appreciation to the data collectors and supervisors who participated in the study. We are also grateful to all study subjects who participated in the study.

\section{References}

1. UNDO/UNFPA/WHO (2003) Special Program of Research Development and Research Training in Human Reproductive Health (HRP), Progress in Reproductive Health Research. World Bank 64.

2. Conger A (1991) Adolescence and Youth. Harbor Collins publishers, New York.

3. Taylor-Seehafer M, Rew L (2000) Risky sexual behavior among adolescent women. J Soc Pediatr Nurs 5: 15-25.

4. UNFPA (1997) The State of World Population, Geneva.

5. Central statistical authority (CSA) and ORC Macro (2011) Ethiopian demographic and health survey, Addis Ababa, Ethiopia. CSA and ORC Macro.

6. FHI, USAID, Youth Net Assessment Team (2004) Assessment of youth reproductive health programs in Ethiopia.

7. Barbara S, Monica J, Grant A, Blanc K. The Changing Context of Sexual Initiation in Sub- Saharan Africa. Pop Counsil.

8. United Nations Children's Fund (2002) Young People and HIVIAIDS Opportunity in Crisis. UNICEF, New York.

9. Tilahun M, Ayele G (2013) Factors associated with age at first sexual initiation among youths in GamoGofa, South West Ethiopia: A cross sectional study. BMC Public Health 13: 622.

10. Oljira L, Berhane Y, Worku A (2012) Pre-marital sexual debut and its associated factors among in-school adolescents in eastern Ethiopia. BMC Public Health 12: 375 .

11. Ethiopian Public Health Association (EPHA) (2003) Adolescent Reproductive health global and national initiatives and lessons learned. EPHA ARH Task Force.

12. HIVIAIDS Prevention and Control Office (HAPCO) (2000) Behavioral Surveillance Survey (BSS) in Ethiopia.

13. Mullu G, Berhane E, Abebe N (2014) Prevalence of premarital sexual practice and associated factors among alamata high school and preparatory school adolescents, Northern Ethiopia. Global journal of medical research 14: 1.

14. Alemu A, Letta S, Demessie M (2015) Premarital sexual practice and its associated factors among high school adolescents in kolfekeraniyo sub city, Addis Ababa Ethiopia: A cross sectional study. International Journal of Development Research 5: 3359-3364.

15. Seme A, Wirtu D (2008) Premarital sexual practice among school adolescents in Nekemte Town, East Wollega. Ethiop J Health Dev 22: 167-173.

16. Shiferaw Y, Agersew A, Girma A, Getahun A, Kassa A, et al. (2011) Assessment of knowledge, attitude and risk behaviors towards HIVIAIDS and other sexual transmitted infection among preparatory students of Gondar town, North West Ethiopia. BMC Research Notes 2011 4: 505.

17. Tilahun M, Ayele G (2013) Factors associated with age at first sexual initiation among youths in GamoGofa, South West Ethiopia: A cross sectional study. BMC Public Health 13: 622.

18. Tura G, Alemseged F, Dejene S (2012) Risky sexual behavior and predisposing factors among students of Jimma University. Ethiop J Health Sci 22: 170-180.

19. HIVIAIDS Prevention and Control Office (HAPCO) (2000) Behavioral Surveillance Survey (BSS) in Ethiopia.

20. Mitike M, Yemane B, Bernt $L$ (2008) Traditional values of virginity and sexual behavior in rural Ethiopian youth: Results from a cross-sectional study. BMC Publ Health 8: 9. 
Citation: Endalew D, Gebremichael B, Tesfa M, Asmamaw T (2018) Premarital Sexual Practice and Risky Sexual Behaviors Associated with it among Secondary School Adolescents, South East Ethiopia: A Mixed Design Study. J AIDS Clin Res 9: 775. doi: 10.4172/2155-6113.1000775

Page 7 of 7

21. Santrock JW (2006) A Review of Life Span Development, 10th-ed. McGraw Hill Camp, Boston.

22. Shiferaw Y, Agersew A, Girma A, Getahun A, Kassa A, et al. (2011) Assessment of knowledge, attitude and risk behaviors towards HIVIAIDS and other sexual transmitted infection among preparatory students of Gondar town, North West Ethiopia. BMC Research Notes 4: 505
23. Benti T, Negaro A, Kebede A (2015) Prevalence of premarital sexual practice and associated factors among undergraduate health science students of Madawalabu University, Bale Goba, South East Ethiopia: institution based cross sectional study. Pan African Medical Journal 20: 209. 